This item was submitted to Loughborough's Research Repository by the author.

Items in Figshare are protected by copyright, with all rights reserved, unless otherwise indicated.

\title{
A framework for a more efficient approach to food waste management
}

\section{PLEASE CITE THE PUBLISHED VERSION}

http://dx.doi.org/10.18178/ijfe.1.1.65-72

\section{PUBLISHER}

(c) International Journal of Food Engineering

\section{VERSION}

AM (Accepted Manuscript)

\section{PUBLISHER STATEMENT}

This work is made available according to the conditions of the Creative Commons Attribution-NonCommercialNoDerivatives 4.0 International (CC BY-NC-ND 4.0) licence. Full details of this licence are available at: https://creativecommons.org/licenses/by-nc-nd/4.0/

\section{LICENCE}

CC BY-NC-ND 4.0

\section{REPOSITORY RECORD}

Garcia-Garcia, Guillermo, Elliot Woolley, and Shahin Rahimifard. 2019. "A Framework for a More Efficient Approach to Food Waste Management”. figshare. https://hdl.handle.net/2134/18195. 


\title{
A Framework for a More Efficient Approach to Food Waste Management
}

\author{
Guillermo Garcia-Garcia \\ Loughborough University, Leicestershire, United Kingdom \\ Email: G.Garcia-Garcia@lboro.ac.uk \\ Elliot Woolley and Shahin Rahimifard \\ Loughborough University, Leicestershire, United Kingdom \\ E.B.Woolley@lboro.ac.uk, S.Rahimifard@lboro.ac.uk
}

\begin{abstract}
A considerable amount of waste is generated in the food supply chains of both developing and developed countries. In an increasingly resource constrained world, it is imperative to reduce the high environmental, social and economic impacts associated with this type of waste. This necessitates the development and implementation of improved, targeted management practices. This paper discusses the various definitions and categorisations of food waste according to different international organisations, reviews the most up-to-date data on waste generated in the food supply chains as well as its environmental impact and assess the applicability of current waste management options. This analysis provides the basis for the development of a framework for increasing the effectiveness of food waste management practices through structured assessment and better informed selection of waste management methodologies for each food waste category. The usability of this novel framework is discussed.
\end{abstract}

Index Terms-food waste, waste management, waste categorization, environmental impact, waste hierarchy.

\section{INTRODUCTION}

Approximately one third of the edible parts of food produced worldwide are never consumed; this is estimated to be 1.3 billion tonnes per year [1]. Based on energy content, the calories contained within global food waste represent close to $24 \%$ of all food produced (around 1.5 quadrillion kcal) [2]. These massive numbers have not attracted significant public and scientific attention over the last few decades: waste generation has typically been considered as an inevitable issue in food supply chains.

The common approach in the last century to feed the exponentially growing global population has been through an increase in total food production. This has been done principally through improvements in crop productivity (strongly influenced by developments of better fertilizers and pesticides). However, in today's world with a continuously growing population and dietary shifts in emerging economies towards more resource intensive foods (e.g. meat consumption is expected to rise by $46 \%$ and $94 \%$ respectively in China and India [3]), a rise in food production is not enough. Reducing food waste and optimising its treatment is one way to make the food supply chain more efficient and sustainable.

The food-waste issue is affected by environmental factors (such as climate change and contamination of air, water and land) and social factors (including the aforementioned population growth and new trends in consumerism). Consequently, food waste impacts on society, the environment and the economy in both developing and developed countries. This is represented in the Fig. 1 together with the proposed approach to address the food-waste issue.

It has been reported that globally as many as 842 million people suffer from chronic hunger in the world nowadays [4], even when current food production levels

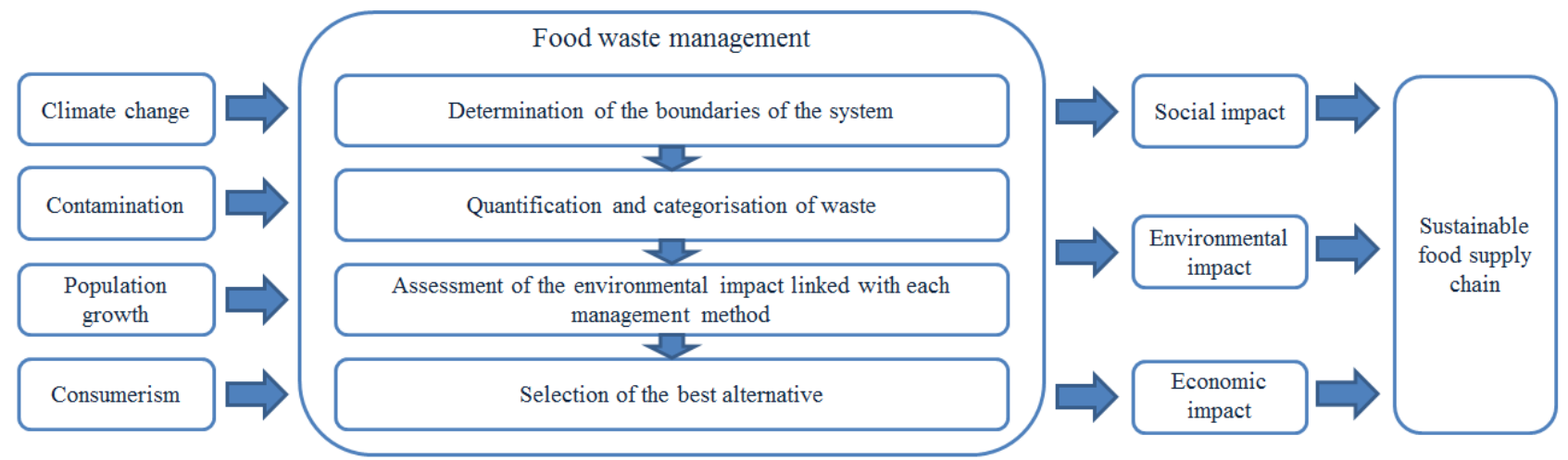

Figure 1. Global issues affecting the food waste issue, proposed approach to deal with it and wider impacts. 
would be enough to feed the entire human population [5]. However, this is not only a distribution problem, since [3] estimates that after distributing all the food produced in 2009 amongst the global population the world would still need to produce 974 more calories per person per day by 2050, 69\% more than in 2006 (the United Nations predicts that the human global population will reach 9.6 billion in 2050 [6]). Reference [3] suggests that cutting food waste in half would close this food gap by $20 \%$.

Furthermore, food waste contaminates land, air and water. Greenhouse gas emissions, water footprint, occupied land, eutrophication, acidification, resource depletion and photochemical oxidation are the most important indicators to measure this impact [7].

In addition to the aforementioned social and environmental effects, food waste also has an important economic impact. Reference [8] estimates that the total cost of food waste can reach USD one trillion each year; to this number should be added an additional USD 700 billion related to the environmental impact and USD 900 billion associated with social costs.

A reduction of the current waste levels is imperative in order to make a more sustainable food supply chain. Special attention should also be focused to find the best alternatives to deal with food waste once it has been generated. Though efforts have been made in recent years, there is still a large challenge to reduce the impacts discussed above.

This research bridges part of this knowledge gap by providing a framework to optimize decision-making regarding food waste management. The paper begins with a detailed review of current literature pertaining to food waste categorisation, associated environmental impacts and management, and defines a novel framework consisting of four stages: clear definition of food waste and the boundaries of this term; categorisation and quantification across supply chains; assessment of environmental impacts; and selection of most appropriate technology/management option. The described framework is universally applicable (e.g. to a specific region, stage of the supply chain, industry, type of waste) as is discussed in the latter sections of this paper.

\section{CURRENT FoOd WASTE MANAGEMENT}

\section{A. Food Waste Definition}

According to the Waste Framework Directive by the EU law [9], waste is 'any substance or object which the holder discards or intends or is required to discard'. However, there is not a consensus about the exact meaning of the term "food waste". The Food and Agriculture Organisation of the United Nations [1] distinguishes between the so-called "wastage" produced mainly in the beginning of the supply chain (during production, post-harvest and processing stages), called food loss, and the wastage generated principally at the end of the supply chain once the food has been processed, known as food waste. The disadvantages of this definition are the difficulty to measure and report these parameters separately; in addition the concepts "food loss" and "food waste" can cover different stages of the supply chain for different food products or geographical areas (e.g. biscuits produced in a factory or directly in the point of sale). By contrast, the project funded by the European Commission Framework Programme 7 named Food Use for Social Innovation by Optimising Waste Prevention Strategies (FUSIONS) [10] and the UK Waste \& Resources Action Programme (WRAP) [11] refer to both of these concepts as food waste.

Another major discrepancy is the consideration of the inedible parts of food as food waste. FAO only count the parts of the food that could have been eaten by people. FUSIONS and WRAP also include inedible parts of food (such as bones or egg shells) in the definition of food waste. The quantification and treatment of separate edible and inedible parts of the food is normally difficult, and commonly unfeasible (a wasted orange will normally consist of the inedible peel and the edible orange itself and will not be peeled for its treatment).

There is also disagreement regarding the intended uses of the food: the planned use of it in another way other than for human consumption (such as animal feed or rendering) is not considered as food waste in any case, while the unplanned use of it in a non-food use is considered food waste by FAO but not by FUSIONS and WRAP. The distinction between planned and unplanned non-food use is very relative and unclear, as some producers may not plan how much of their product is going to be directed for human consumption and how much for other use. Furthermore, the same food product in the same stage of the supply chain could either be considered or not considered waste according to different criteria.

The Fig. 2 highlights the different terms included in the term 'food waste' according to the aforementioned organisations and considerations.

Because of the reasons mentioned above, the authors consider that the definition proposed by FUSIONS is preferred: 'Food waste is any food, and inedible parts of food, removed from the food supply chain to be recovered or disposed (including composted, crops ploughed in/not harvested, anaerobic digestion, bio-

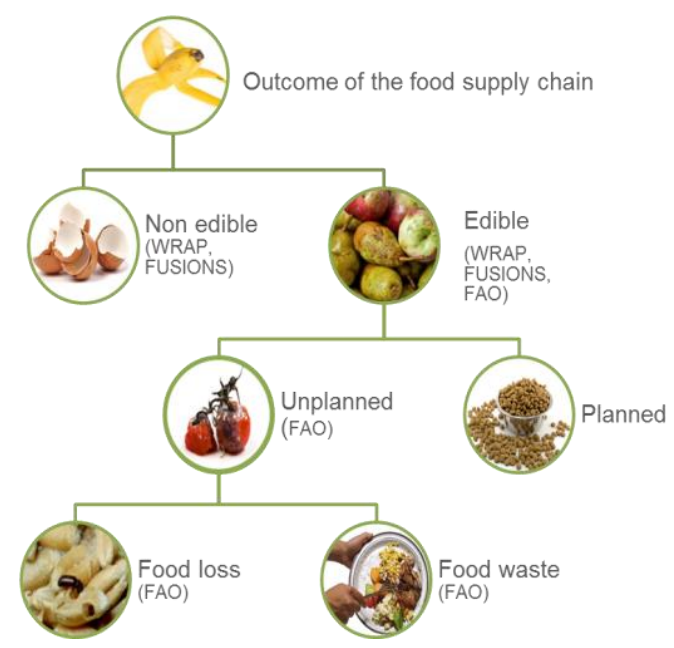

Figure 2. Definitions of food waste according to different organizations. 
energy production, co-generation, incineration, disposal to sewer, landfill or discarded to sea)' [10]. This definition includes drinks; but does not cover redistribution, packaging waste and food and inedible parts of food sent to animal feed.

\section{B. Quantification and Categorisation}

The substantial amount of food waste generated worldwide divides unequally among the different areas of the world. Developed countries generate more waste than developing countries: in North America and Europe edible food waste reach 280-300 kg/capita per year while in sub-Saharan Africa and South and Southeast Asia it is only between 120 and $170 \mathrm{~kg} /$ capita per year [1]. The relation between food wasted and food produced expressed as a percentage can be seen in the Fig. 3 .

Apart from the differences regarding the total food waste, waste across the supply chain also varies across the different stages and the different areas of the world. Reference [1] explains that in developing countries food waste is generated mainly in the beginning of the supply chain (caused by deficiencies in transportation and infrastructures and poor harvesting technologies [12]) and in developed countries in the end of the supply chain, mostly at a consumer level (strongly influenced by new trends in consumerism and mass marketing [12]). Some analyses on this situation have been carried out measuring waste in terms of energy (kcal) lost instead of weight (kg or ton) of waste. Reference [2] also estimates the main differences are at consumption stage: $7 \%$ of the edible parts of food are wasted (based on kcal) at this stage in developing countries, and up to $28 \%$ in developed areas; the differences in the other stages of the supply chain are much smaller. Reference [13] additionally calculated the amount of food produced for uses other than human consumption (such as animal feed and seed); in this global approach only $16 \%$ of the food calories are wasted.

Usually, categorisation of food waste is achieved by type of product only. In this way, reference [2] estimates that the most common food products which become waste are fruits and vegetables (44\% of the total food waste, by weight), followed by roots and tubers (20\%) and cereals (19\%). However, the amount of waste is not the only consideration that should receive attention: only $4 \%$ of the waste corresponds to meat, although it has high environmental and economic impacts associated with it. In addition to this categorisation, reference [11] classifies food waste in three types: avoidable if it is or has been edible (part of the food products that is eatable), unavoidable if it has never been edible (e.g. orange peel), and possibly avoidable if some people would have eaten and others do not (e.g. bread crusts) or could have be eaten when the food is prepared in one way but not in another (e.g. potato skins). Usually, unavoidable food waste corresponds to by-products created or separated in the food supply chain.

These simple categorisations do not provide enough information to select the best available alternative to deal with food waste. Efforts should be made in classifying

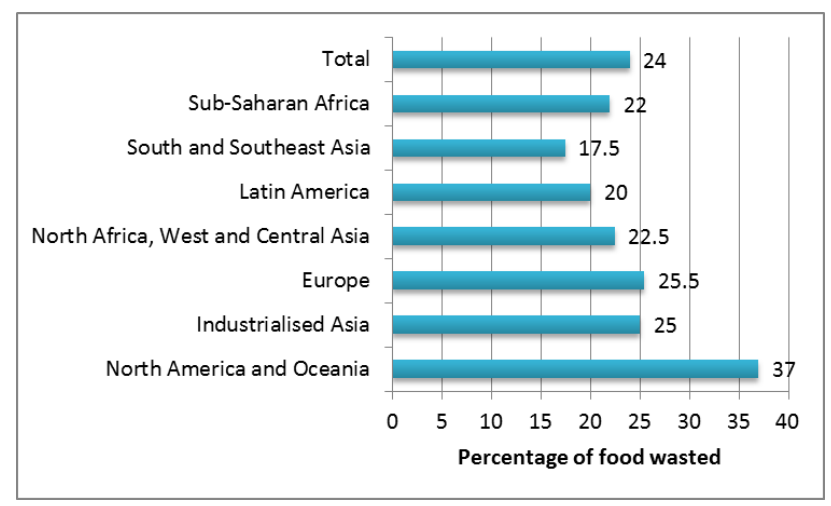

Figure 3. Percentage of edible parts of food wasted (in kcal) in the different areas of the world. Average data from [2] and [13].

waste in more relevant categories, and afterwards, in its segregation according to the types of waste.

\section{Environmental Impact}

Food waste has very important environmental ramifications, taking into account the treatment of the waste and the production of food that ends up being wasted. Several indicators can be used to measure this environmental impact; nevertheless the most widely used and well known are the carbon footprint, blue water footprint and land occupation.

A carbon footprint is the total amount of greenhouse gas (GHG) emissions caused directly and indirectly by an activity or accumulated over the life stages of a product. This indicator should quantify the most important GHG emissions, including carbon dioxide $\left(\mathrm{CO}_{2}\right)$, methane $\left(\mathrm{CH}_{4}\right)$ and nitrous oxide $\left(\mathrm{N}_{2} \mathrm{O}\right)$, which are considered the most important GHG up to farm gate [14]; carbon dioxide is also the most significant in the rest of the UK food supply chain (mostly from fossil energy use). The carbon footprint associated with global food waste is $3.3 \mathrm{Gt}$ $\mathrm{CO}_{2}$ eq per year, with Asia being the major contributor (mainly due to cereal waste) [15]. Reference [14], based on estimations of [16], proposes that the emissions related to food disposal contribute only a $2 \%$ on the total GHG emissions of the UK food supply chain, excluding land use change. However, it is worth remembering that the impacts of previous phases add up in each stage. Although this contribution can be expected to be similar in other developed countries, it is unknown in developing areas: common disposal options for food waste such as landfilling can counterbalance their inefficient food production and transportation. Yet, preventing food waste generation to reduce the carbon footprinting associated with waste across the food supply chain is paramount.

Reference [17] distinguishes three types of water footprint: blue, green and grey, and defines blue water footprint, the most relevant to the food-waste issue, as the total consumption of surface and groundwater resources to produce the product. Globally, it is around 250 $\mathrm{km}^{3} /$ year, with an average 38,0001 per capita per year [15]. The water footprint varies largely between different products: cereals and fruits contribute the most to the blue water footprint (52\% and $18 \%$ respectively) as high proportions of these products end up being wasted [15]. Animal products commonly have a higher water footprint 
per $\mathrm{kg}$ of food product due to the large amounts of water required to grow animal feed crops. Improvements must be fundamentally applied to agricultural activities, since $70 \%$ of the total water consumed worldwide corresponds to the agricultural stage; for example, switching from the inefficient flood and overhead spray irrigation systems to drip and trickle irrigation is recommended to reduce water consumption [12].

Furthermore, food which ultimately ended up as waste occupied nearly 1.4 billion hectares in 2007, about $28 \%$ of the world's agricultural land area [15]. This is about $2000 \mathrm{~m}^{2}$ per capita per year. However, it is much higher in North Africa and Western and Central Asia because of the low-yield grasslands used to feed the livestock: $27 \%$ of the occupied land by food waste corresponds to these regions [18]. Reference [15] states that meat and milk have the highest impact per $\mathrm{kg}$ of product, occupying mainly non-arable land.

In Europe, $89 \mathrm{Mt}$ of food waste generated each year produce around $170 \mathrm{Mt}$ of $\mathrm{CO}_{2} \mathrm{eq}$, with an average $1.9 \mathrm{t}$ of $\mathrm{CO}_{2} \mathrm{eq} / \mathrm{t}$ of food wasted [7]. Reference [7] also evaluated the impact of food waste through different indicators: acidification (2563 kt $\mathrm{SO}_{2}$ eq/year), photochemical oxidation (666 kt NMVOCeq/year) and resource depletion (261 Mt/year). These estimations do not include end-of-life impact, so the overall environmental impact is even higher.

Further work to minimise this impacts is required, but also to evaluate the environmental ramifications of food waste. There is a need to harmonise the measuring methods to asses this impact. In spite of its complexity, a Life-Cycle Assessment approach (LCA) is preferred, as it systematically evaluates the impact of waste management options and also of the food in the supply chain that becomes waste. This methodology has already been successfully used by [19], [20] and [21], among others.

\section{Waste Management Options}

In 2008, the European Parliament and the Council of the European Union introduced the Waste Framework Directive 2008/98/EC [9]. It contained a five-step waste hierarchy that must be applied by all the Member States. The most preferred management options when tackling food waste are prevention of food-waste generation and redistribution of the surplus food. Once the waste is created, the priority is to recycle it into a second use, followed by recovery treatment and then disposal as the least preferred option. The most common alternatives for each stage are discussed below.

The most preferred option is to prevent the surplus of food from being created. This, from farms to retailers, can be translated into improving processes and their control. Prevention of food waste generation during manufacturing can be also reached giving a different use to a food rejected for its original purpose (e.g. a carrot that has an unfavourable shape for sale as a whole can be cut into pieces to be used as an ingredient in a readymeal). On the other hand, consumers must make an effort to use the food they buy in good time, not cook, serve or order too much, store the food in good conditions and avoid rejecting the food because of aesthetic reasons (unless it can be a signal of spoiled food). There are many initiatives which aim to raise awareness of wasting food at consumer level.

If there is an unavoidable surplus of food, the best option is redistributing it to people in need. There are already organisations which manage redistribution of this excess of food, but society must pay more attention to this option. This is the best use for avoidable food waste. If redistribution to people is not possible, redistribution to animals should be considered. The use of food waste as feed is applicable to some types of avoidable, possibly avoidable and unavoidable food waste.

Once the waste is generated, and if it cannot be redistributed, altering it to obtain a second application is the next best option. One option is the extraction of some compounds of interest: fat and proteins can be separated from meat and fat trimmings via rendering plants and can then be used for animal feed. In the case of fat, it can also be used to produce fuel, soap and other products. Essential oils, aromas and colourings can also be extracted from vegetables and fruits. Another option is anaerobic digestion, a biological process in which organic waste is decomposed by naturally occurring bacteria in the absence of oxygen to obtain biogas. The biogas, mainly methane, can be used to generate fuel, heat or electricity, or can be directed into the gas grid. The solid waste that was not converted into biogas, called digestate, can be used as a fertilizer [22]. In recent years it has become a commonly accepted way of managing food waste. Unlike anaerobic digestion, composting is a process in which microorganisms decompose organic waste using oxygen. The outcome obtained is a nutrient rich soil conditioner called compost. Composting can be carried out at an industrial level and at households. References [23] and [24] suggest that anaerobic digestion is environmentally better than composting.

Thermal treatments with energy recovery include incineration, pyrolysis and gasification. These processes differ mainly in the temperature reached (between $400^{\circ} \mathrm{C}$ and $1200{ }^{\circ} \mathrm{C}$ ) and the outcomes generated (carbon dioxide, carbon monoxide, water, nitrogen oxides, hydrogen, methane and other hydrocarbons in the gaseous phase; ash, slag, coke and char in the solid phase) [25]. These treatments are less efficient than coalfired power stations and generate ashes and noxious pollutants to human health that also have a negative effect on water, soil and air [22]. Nevertheless, it replaces the combustion of fossil fuels, and food waste can be considered as a renewable material. On the other hand, landspreading is the process of coating the food waste to the soil. It should provide agricultural benefits, i.e. by enhancing the physical, chemical and biological characteristics of the soil so the crops can grow better. Thus the amount of sand, silt and clay, organic matter content, depth and underlying geological parent material must be tested in the soil before deciding the convenience of landspreading [26].

Disposal of food waste is the last preferred option. Thermal treatment without energy recovery consists simply of burning the waste, sometimes in open air and 
without material recovery. The only advantage of this method is the reduction of the volume of waste. However, the heat is lost and the outcomes of the process (i.e., combustion gases and ash) are toxic. The gases also increase the greenhouse effect. Landfilling is still the most common end-of-life management options in the world [22], although some developing countries are making considerable efforts to divert waste sent to landfill. In fact, in the EU $40.4 \mathrm{Mt}$ of food waste was sent to landfill in 2006, and it is intended to reduce this number by $90 \%$ by 2020 , to $4 \mathrm{Mt}$ [7]. The outcomes generated during microbiological reactions can contaminate the atmosphere, water and land, spreading diseases that can affect the humans [22].

\section{FOOD WASTE MANAGEMENT FRAMEWORK}

Without agreed consensus on how to measure or even categorise waste, it is difficult to design a waste management strategy for a particular scenario. In this respect there is a need for a framework which provides a structure around which to assess various types of waste at various stages in the supply chain, evaluate their environmental impact and provide informed guidance on the most appropriate methodology or technology to implement to address these particular waste issues. This section of the paper outlines the development of a novel framework to meet this need.

\section{A. New Way of Categorising Food Waste}

Categorisation is a key step in order to choose the best management option to treat food waste. To date, this classification simply distinguishes among the different food products (e.g. meat waste and fruit waste), where in the supply chain this waste generates and very general characteristics of the food waste (e.g. edible and inedible parts of the food). A better understanding of the different types of wastes created in the food supply chain will not only enable selection of a management option where the environmental impact is minimised, but also maximise the social benefit and the economic output of the process.

A nine-stage categorisation is proposed. This is based in nine characteristics that the authors consider the most important in order to prioritise the best management options for each kind of waste. The assessment of each stage has been simplified in a way that there are only two or three types of waste in each step of the process. Waste categorisation using this approach is described below and in the Fig. 4.

Firstly, waste should be identified as edible or inedible. Inedible wastes are typically by-products obtained during production at farms or manufacturing, such as twigs, peels, stones, bones, offal, etc. Edible waste is defined as the parts of the food expected to be consumed by humans, like tomatoes, meat, bread and so on; nevertheless, in this context, products that contain both edible and inedible parts are considered as edible (i.e. a whole orange is considered edible waste, even when it has an inedible peel; or an egg, contained in a shell).

In addition to its edibility, waste should be identified as eatable, if it still has the appropriate properties to be consumed in the moment of disposing. Uneatable waste can be a product which expiration date has passed, that is rotten, or that has been badly processed (e.g. a loaf of bread that has been cooked for too long and has been burnt). The aim of these two stages is the identification of waste that is both edible and eatable, which preferred management option is redistribution to people. In addition, spoiled and damaged food waste discard animal feed as an alternative.

Waste is animal based if it was part of an animal (e.g. meat, bones, offal) or if it was produced by an animal (e.g. eggs, dairy products, honey). Otherwise, it is classified as plant based. Regarding its complexity, the waste is mixed if there are different types of foods in the product (as in ready meals).

The so-called "animal-product presence" stage is divided into two. If the waste has been identified as animal based, it must be further classified as meat (including fish), animal product (such as eggs, dairy products, honey) and by-products from animal bodies not intended for human consumption (like hides, skins, horns, offal, etc.). By-products from the last category mentioned should preferably follow treatments to recover compounds of interest, such as rendering to obtain fat that can be used to produce soaps. These by-products, together with meat, are banned from being used for animal feed according to EU Regulation No 1069/2009 [27]. These rules also apply to plant-based waste that has been in contact with animal-based products (specifically meat and by-products from animal bodies, animal products will be considered later on) to prevent disease
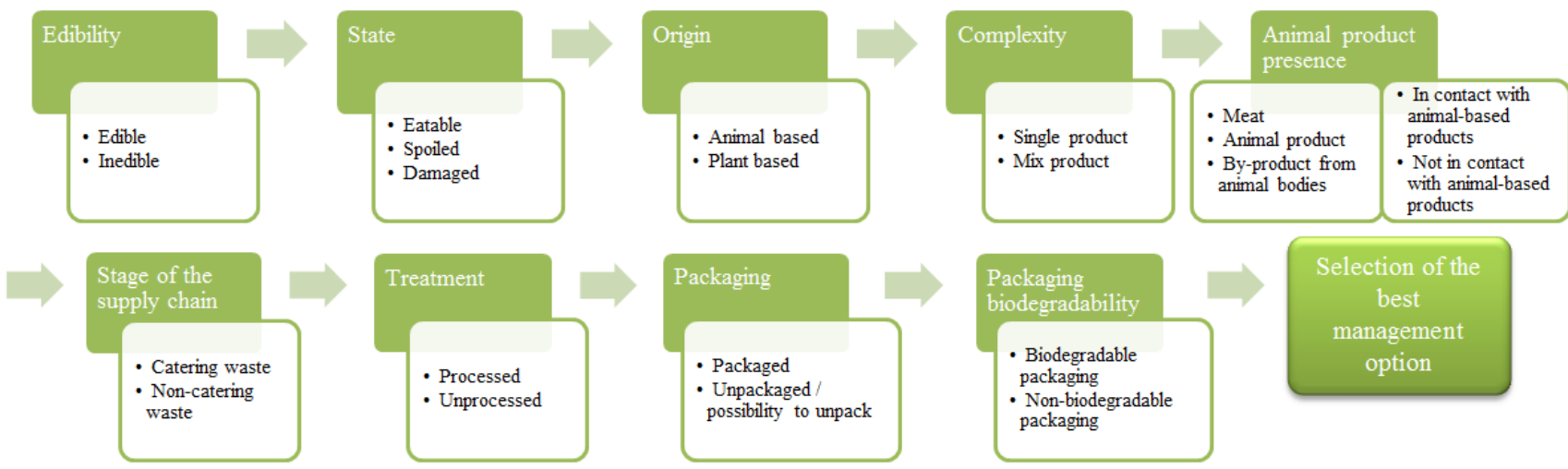

Figure 4. Nine-stage categorization of food waste. 
outbreak [27]. In-vessel composting is the only method that can be used to compost animal-based products or other waste that has been in contact with it [23].

Household waste and waste from food services (i.e. hotels, restaurants, hospitals, etc.) are considered catering waste and according to law must not be used for farmed animal feeding. This regulation came into force in 2001 in the UK and 2003 in the EU [28]. Animal products can be used for animal feeding if they have been properly processed [27]. Animal-based products must be processed to be used for landspreading with the exception of milk used in the farm where it was obtained, and eggshells and shellfish shells under specific conditions [29].

If unpacking technology is available or the separation of the foodstuff and the package is easy, packaged food can be considered as an unpackaged product. Otherwise, the biodegradability of the package must be assessed. If it is not biodegradable, the product must not undergo anaerobic digestion, composting or landspreading.

This analysis can be applied to every kind of food waste produced in the food supply chain. It provides a basis for the study of waste in a food sector, food supply chain, industry or region. This categorisation facilitates the selection of the most appropriate waste management methods, which are discussed in the next section.

\section{B. Selection of the Best Waste Management Options}

A sound categorisation provides the base for better decision-making when selecting management options to deal with food waste. During this process, relevant regulations must be consulted, and environmental, social and economic impacts must be taken into account.

Fig. 5 represents the well-known waste hierarchy (reduce, reuse, recycle, recover and disposal) applied to the case of food waste, showing in the top the best alternatives and in the bottom the worst. This particular order focus on the environmental impact of each treatment, but also takes into account economic and social benefits. Categories of waste which should not undergo certain treatments are described on the left of the figure. The substances and compounds obtained in each methodology, as well as their applications or the benefits obtained, are shown on the right. The different management options, considering the aspects described in the previous section, are explained below.

Limitation of food waste is always preferred, followed by food redistribution to people before the surplus food becomes waste. According to the categorisation proposed before, edible and eatable foodstuff should be reallocated to people.

Food waste must not be redistributed to animals if it contains meat, by-products from animal bodies, raw animal products, or products that have been in contact with them [27]. Catering waste cannot be used as animal feed either [28]. Using waste as animal feed saves crops to be used with this purpose, therefore minimise the water and fertiliser use and it provides an environmental benefit. This option is optimal for inedible parts of food such as spent hops from breweries, and it is also recommended for some edible foods like bread from bakeries and whey from dairies [30].

There are a significant number of compounds in food waste that can be extracted and used with different applications. Some of the extraction processes require complex technology, but the substances obtained are normally of high value. There is an increasing research interest in this area over the last few years; nevertheless for most types of food wastes industrial-scale technologies are not available. Furthermore, after extracting compounds from waste there will be some residue to treat.

Anaerobic digestion and composting are typical treatments for mixed food waste. They both can be employed with all types of waste; however composting must be carried out in-vessel if the waste is meat or byproducts from animal bodies, or the waste has been in contact with them [23]. Packaging is the only factor that can present a problem for these options: if it is not feasible to unpack to waste, the package must be biodegradable (as paper or cardboard). Composting is an

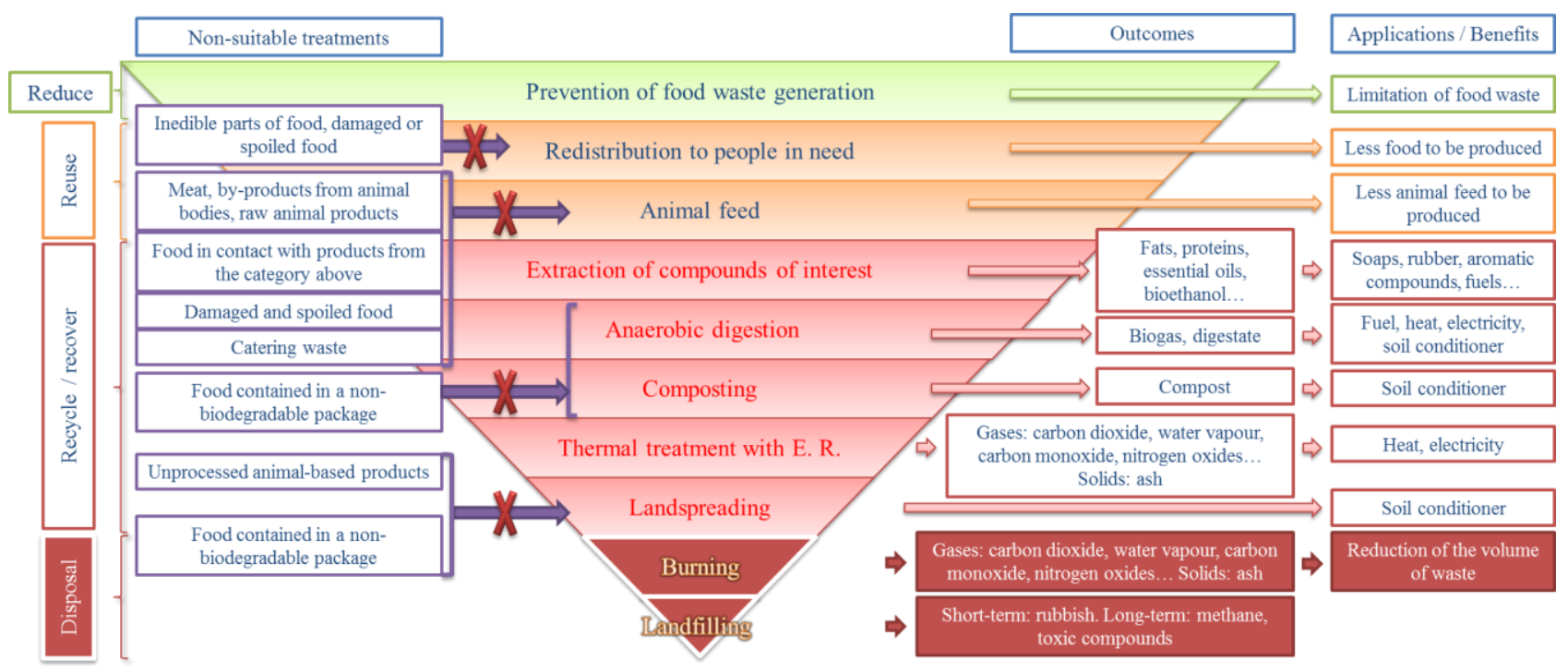

Figure 5. Food waste hierarchy and assessment of the different waste management alternatives. 
easier process than anaerobic digestion and can be also employed at the household level.

Thermal treatments of food waste with energy recovery present some advantages. The processes are normally easy and fast to carry out. In addition, they can be used for every type of waste, including packaging. The disadvantages are the pollution emitted and the low efficiency of the processes.

At the farm stage, landspreading can be a good alternative as farmers can spread waste, typically inedible parts of plant-based products harvested to their soil, and waste does not have to be transported. The waste can provide nutrients to the soil and therefore an agricultural benefit is obtained [26]. This option is not suitable for unprocessed animal-based products (apart from milk, which can be used in the same farm where the cows were milked, and eggshells and shellfish shells in specific situations) [29], and foods contained in a nonbiodegradable packaging.

Disposal options, as thermal treatments without energy recovery and landfilling, are especially discouraged. Waste sent to landfill can be buried or not, but in both situations landfilling has a stronger environmental impact than incineration [22].

The approach proposed in this paper is illustrated by the example displayed in the Table I. The nine-stage analysis is firstly applied, so the food waste product (a beef steak contained in a plastic package) is precisely categorised. Afterwards, the waste hierarchy showed in the Fig. 5 is evaluated for the case of the specific waste to be treated. From top to bottom, each step is studied: the nine characteristics identified during categorisation should prevent some methodologies from being applied, due to their inappropriate nature (high environmental impact, small positive outcome generated) or because they are banned according with national or international law (in the present analysis, UK and EU law was used). The higher management option in the waste hierarchy which passes this selection process should be applied. In the example, three treatments were selected and ordered according to their convenience for implementation. Although extraction of compounds of interest is above anaerobic digestion in the waste hierarchy, this management option was discarded because there is not any relevant available technology at an industrial scale which is appropriate for the example mentioned.

TABLE I. EXAMPLE OF CATEGORIZATION OF WASTE AND SELECTION OF OPTIMAL MANAGEMENT OPTIONS

\begin{tabular}{|ll|}
\hline \multicolumn{1}{|c|}{ Criteria } & Beef steak contained in a plastic package \\
\hline Edibility & Edible \\
State & Spoiled \\
Origin & Animal-based \\
Complexity & Single product \\
Animal product presence & Meat \\
Stage of the supply chain & Manufacturing \\
Treatment & Processed \\
Packaging & Packaged \\
Packaging biodegradability & Biodegradable \\
\hline & 1.- Anaerobic digestion \\
Best management option & 2.- In-vessel composting \\
& 3.- Thermal treatment with energy recovery \\
\hline
\end{tabular}

\section{CONCLUSIONS}

The generation of waste in the food supply chain has associated environmental, social and economic impacts. In order to reduce the amount of wasted food and its negative ramifications, a clear definition of "food waste" and a precise and accurate classification of the different food waste categories are essential. The authors believe the most convenient and complete definition of "food waste" is provided by the European project FUSIONS, as it includes inedible parts of food and does not distinguish between food loss and food waste.

As part of the framework described in this paper, food waste is categorized in nine stages. The result is a range of characteristics, namely edibility, state, origin, complexity, animal product presence, stage of the supply chain, treatment, packaging and packaging biodegradability, each of which determines a specific approach to manage. The available and most common waste management technologies have been assessed and ordered according to their positive outcomes and negative impacts. The environmental impacts associated with food waste and its management, together with economic and social benefits, have also been evaluated.

Prevention of food becoming waste is the preferred option, followed firstly by redistribution to people (if food is edible and eatable) and secondly by redistribution to animals (this option is ideal for manufacturers which produce plant-based products). If surplus food cannot be reused, the valuable compounds contained in the waste, as well as the technologies available, should be assessed. Anaerobic digestion is becoming a more popular way to deal with food waste, and together with composting it can be used to treat every biodegradable waste. Thermal treatments with energy recovery can be used with all types of waste; however it presents important environmental ramifications, such as gas emissions and ash. Landspreading is typically used with plant-based products at the agricultural stage. Thermal treatments without energy recovery and landfilling should be avoided where at all possible because of their environmental impact and lack of positive outcomes.

In spite the growing number of publications addressing this issue, global agreements must be reached on defining unequivocally the concept of food waste and measuring its effects, principally the environmental impact. Optimized analysis methods will provide more reliable data and a clear direction on where efforts must be directed to tackle the food-waste problem.

\section{REFERENCES}

[1] J. Gustavsson, C. Cederberg, U. Sonesson, and R. van Otterdijk, "Global food losses and food waste - Extent, causes and prevention," Rome, Italy: Food and Agriculture Organization of the United Nations (FAO), 2011

[2] B. Lipinski, C. Hanson, J. Lomax, L. Kitinoja, R. Waite, and T. Searchinger, "Reducing food loss and waste," Working Paper, Installment 2 of Creating a Sustainable Food Future. Washington, DC: World Resources Institute, May 2013.

[3] T. Searchinger, C. Hanson, J. Ranganathan, B. Lipinski, R. Waite et al., "Creating a sustainable food future. A menu of solutions to sustainably feed more than 9 billion people by 2050," Washington, DC: World Resources Institute, 2013. 
[4] Food and Agriculture Organization of the United Nations (FAO), International Fund for Agricultural Development (IFAD), and World Food Programme (WFP), "The state of food insecurity in the world 2013. The multiple dimensions of food security," Rome, Italy, 2013

[5] Food and Agriculture Organization of the United Nations (FAO), "The state of food insecurity in the world," Rome, Italy, 2002.

[6] United Nations, Department of Economic and Social Affairs. (June 2013). World population projected to reach 9.6 billion by 2050. [Online]. Available: https://www.un.org/en/development/de sa/news/population/un-report-world-population-projected-to-reach -9-6-billion-by-2050.html (accessed November 2014).

[7] V. Monier, S. Mudgal, V. Escalon, C. O'Connor, T. Gibon et al., "Preparatory study on food waste across EU 27," European Commission (DG ENV), Directorate C - Industry, October 2010.

[8] Food and Agriculture Organization of the United Nations (FAO), "Full-cost accounting. Final report," Rome, Italy, 2014.

[9] European Parliament and the Council of the European Union, "Directive 2008/98/EC of the European Parliament and of the Council of 19 November 2008 on waste and repealing certain Directives," Official Journal of the European Union, I. 312, pp. 330, November 2008 .

[10] K. Östergren, J. Gustavsson, H. Bos-Brouwers, T. Timmermans, O. Hansen et al., "FUSIONS Definitional framework for food waste. Full report," Food Use for Social Innovation by Optimising Waste Prevention Strategies (FUSIONS), July 2014.

[11] T. Quested, and H. Johnson, "Household food and drink waste in the UK. Final report," Banbury: Waste \& Resources Action Programme (WRAP), November 2009.

[12] Institution of Mechanical Engineers, "Global food: Waste not, want not," London, UK, January, 2013.

[13] M. Kummu, H. de Moel, M. Porkka, S. Siebert, O. Varis, and P.J. Ward, "Lost food, wasted resources: Global food supply chain losses and their impacts on freshwater, cropland, and fertiliser use," Science of the Total Environment, vol. 438, pp. 477-489, November 2012.

[14] T. Garnett, "Where are the best opportunities for reducing greenhouse gas emissions in the food system (including the food chain)?," Food Policy, vol. 36, pp. S23-S32, 2011.

[15] Food and Agriculture Organization of the United Nations (FAO), "Food wastage footprint. Impacts on natural resources. Presentation of the FAO FWF study," Food Wastage Footprint project, September 2013.

[16] T. Garnett, "Cooking up a storm. Food, greenhouse gas emissions and our changing climate," Surrey, UK: Centre of Environmental Strategy, September 2008.

[17] A. Y. Hoekstra, A. K. Chapagain, M. M. Aldaya, and M. M. Mekonnen, "The water footprint assessment manual. Setting the global standard," London, UK: Water Footprint Network, 2011.

[18] Food and Agriculture Organization of the United Nations (FAO), "Food wastage footprint. Impacts on natural resources. Summary report," Food Wastage Footprint project, 2013.

[19] S. Lundie, and G. M. Peters, "Life cycle assessment of food waste management options," Journal of Cleaner Production, vol. 13, pp. 275-286, 2005.

[20] H. H. Khoo, T. Z. Lim, and R. B.H. Tan, "Food waste conversion in Singapore: Environmental impacts based on an LCA perspective," Science of Total Environment, vol. 408, pp. 13671373,2010

[21] M. Kim, and J. Kim, "Comparison through a LCA evaluation analysis of food waste disposal options from the perspective of global warming and resource recovery," Science of Total Environment, vol. 408, pp. 3998-4006, 2010.

[22] Food and Agriculture Organization of the United Nations (FAO), "Toolkit. Reducing the food wastage footprint," Food Wastage Footprint project, 2013

[23] Waste \& Resources Action Programme (WRAP), "Applying the waste hierarchy. A guide to business," Banbury, UK, February 2011.

[24] Department for Environment, Food and Rural Affairs (Defra), Waste \& Resources Action Programme (WRAP), and Environment Agency, "Applying the waste hierarchy: evidence summary," London, UK, June 2011.

[25] I. S. Arvanitoyannis, A. Kassaveti, and D. Ladas "Food waste treatment technologies," in Waste Management for the Food Industries, I. S. Arvanitoyannis, Ed. Academic Press, Food
Science and Technology, International Series, 2008, ch 6, pp. $345-$ 410.

[26] Environment Agency, "How to comply with your landspreading permit," TGN EPR 8.01, Version 2, February 2013.

[27] Institute of Grocery Distribution (IGD), "Redistribution to animals," [Online]. Available: http://www.igd.com/ourexpertise/S upply-Chain/WastePrevention/15907/Redistribution-to-animals/ (accessed November 2014).

[28] Department for Environment, Food and Rural Affairs (Defra), "Feeding catering waste to farmed animals is illegal", [Online]. Available: http://www.chippingnortonvets.co.uk/modules/downloa dspl2/files/DEFRA\%20catering\%20waste\%20leaflet.pdf (accessed November 2014).

[29] Defra, and APHA, "Making fertiliser from processed animal byproducts (ABPs)," [Online]. Available: https://www.gov.uk/makin g-fertiliser-from-processed-animal-by-products-abps (accessed November 2014).

[30] The Pig Idea, "The solution," [Online]. Available: http://thepigidea.org/the-solution.html (accessed November 2014).

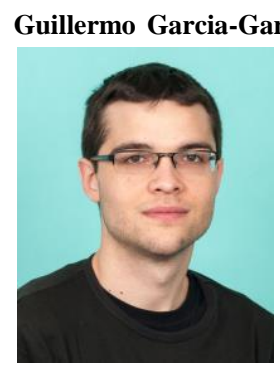

ia earned a MEng in chemical engineering at the University of Granada (Spain) in 2011 and a BEng in industrial technical engineering at the University of Jaén (Spain) in 2012

His experience in the food sector includes positions in the production laboratory of a dairy Spanish company and in the $R \& D$ Department of an edible-casings producer in Germany. He joined Loughborough University in 2014 as a Research Assistant to investigate sustainable manufacturing of food products. $\mathrm{He}$ is also undertaking a $\mathrm{PhD}$ in eco-production of food at Loughborough University.

Elliot B. Woolley has an MPhys in applied physics from the

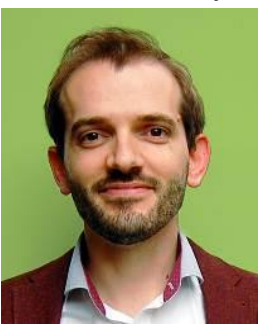

Nottingham Trent University and a $\mathrm{PhD}$ in nuclear magnetic resonance from the University of Nottingham.

He has industrial experience in the food sector including working as a Research and Technology Consultant for Pera Innovation Ltd, where he helped establish a number of research projects for Small and Medium Enterprises operating in the food and drink sector. For the last five years he has worked at Loughborough University and is currently a Lecturer in Sustainable Manufacturing with a particular interest in energy efficient manufacturing and the implementation of low carbon energy sources within manufacturing environments.

Shahin Rahimifard has a BSc in computing and mathematics from

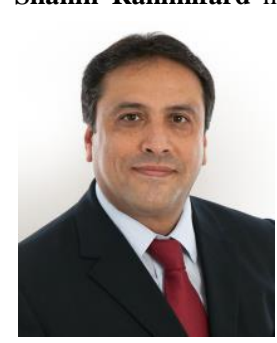
Brighton University, an MSc in computer integrated manufacture and a $\mathrm{PhD}$ in operational planning of manufacturing systems both from Loughborough University.

He has over 20 years of experience in managing $R \& D$ projects within the field of sustainable manufacturing at Loughborough University. As founder and Director of the Centre for Sustainable Manufacturing and Recycling Technologies (SMART) in Loughborough, he has been involved in over 25 national and European research projects. His research interests are sustainable product design, low carbon manufacturing, environmentally focussed production planning and supply chain management, and product recovery, reuse and recycling technologies. He has over 90 publications associated with his work.

Prof. Rahimifard has been the Editor-in-Chief of the International Journal of Sustainable Engineering since 2008 and he is the book review editor for three other international journals. He is also a member of the Technical Committee for four international conferences. 